\title{
Feasibility and Immune Response of WT1 Peptide Vaccination in Combination with OK-432 for Paediatric Solid Tumors
}

\author{
KOICHI HIRABAYASHI ${ }^{1,2}$, RYU YANAGISAWA ${ }^{1,2}$, SHOJI SAITO ${ }^{1,2}$, YUMIKO HIGUCHI ${ }^{1}$, \\ TERUTSUGU KOYA ${ }^{3}$, KENJI SANO ${ }^{4}$, SHIGEO KOIDO ${ }^{5}$, MASATO OKAMOTO ${ }^{6}$, \\ HARUO SUGIYAMA $^{7}$, YOZO NAKAZAWA ${ }^{2}$ and SHIGETAKA SHIMODAIRA ${ }^{3}$ \\ ${ }^{1}$ Center for Advanced Cell Therapy, Shinshu University Hospital, Nagano, Japan; \\ ${ }^{2}$ Department of Paediatrics, Shinshu University School of Medicine, Nagano, Japan; \\ ${ }^{3}$ Department of Regenerative Medicine, Kanazawa Medical University, Ishikawa, Japan; \\ ${ }^{4}$ Department of Laboratory Medicine, Shinshu University Hospital, Nagano, Japan; \\ ${ }^{5}$ Department of Gastroenterology and Hepatology, The Jikei University School of Medicine, Chiba, Japan; \\ ${ }^{6}$ Department of Advanced Immunotherapeutics, \\ Osaka University Graduate School of Pharmaceutical Sciences, Osaka, Japan; \\ ${ }^{7}$ Department of Functional Diagnostic Science, Graduate School of Medicine, Osaka University, Osaka, Japan
}

\begin{abstract}
Background/Aim: Wilms' tumor 1 (WT1) peptidebased vaccination has been reported for its potential usefulness in targeting several cancers. The adjuvant drug OK-432 is known to have potent immunomodulation and therapeutic properties when applied in cancer treatment and may, thus, be important to trigger the appropriate immunological response in paediatric patients with a solid tumor that are vaccinated with a WT1 peptide. Patients and Methods: Paediatric patients with a solid tumor were vaccinated with a WT1 peptide and OK-432 once every 2 weeks, for a total of seven times. Results: Of the 24 patients, 18 completed the scheduled vaccinations. Sixteen patients had local skin symptoms and/or fever. In 1 patient, anaphylactic symptoms emerged at the time of the final injection, but these quickly subsided after the treatment. WT1-specific immunological responses were observed in 4 patients (22.2\%). WTI and HLA class I expression were confirmed in $100 \%$ and $85 \%$ of primary tumors, respectively. Conclusion: WT1 peptide vaccine therapy combined with OK-432 appears to be relatively safe for children. However further studies in a larger number of patients are necessary to confirm its safety and efficacy.
\end{abstract}

Correspondence to: Dr. Ryu Yanagisawa, Center for Advanced Cell Therapy, Shinshu University Hospital, 3-1-1, Asahi, Matsumoto 3908621, Nagano, Japan. Tel: +81 263373240, Fax: +81 263373027, e-mail: ryu@shinshu-u.ac.jp

Key Words: Adjuvant, immunotherapy, pediatric cancer, $\mathrm{T}$ cell, Wilms' tumor 1 .
While the use of multidisciplinary approaches including surgery, chemotherapy and/or radiotherapy has resulted in improved cure rates in paediatric patients with solid tumors (1), many of these patients suffer from a relapse and/or treatment-related complications (2). Cancer immunotherapies, developed to improve survival rates and reduce treatmentrelated complications, have drawn a lot of attention within the past few years.

Wilms' tumor 1 (WT1) protein is a zinc finger transcription factor essential in urogenital embryogenesis. Although, at first, WT1 was identified as a tumor suppressor gene responsible for Wilms' tumors of the kidney (3-5), it possesses an oncogenic, rather than a tumor-suppressive function $(6,7)$. Wild-type WT1 is expressed in many types of haematological and solid tumors, which indicates that WT1-targeting immunotherapy can be used for a variety of malignancies $(8,9)$. Some clinical studies using WT1 peptide vaccine have been reported; however, there are few studies reporting the same in paediatric patients with solid tumors (10).

Despite the usefulness of adoptive cancer immunotherapies using the patient's blood cells such as $\mathrm{T}$ cells and natural killer cells and acquired immunotherapy with dendritic cells (DCs), there are some problems associated with paediatric patients with solid tumors, such as difficulties in harvesting specific materials from blood cells. Therefore, peptide cancer vaccination targeting specific cancer-associated antigens such as WT1 peptide may be one of the important options for such patients. However, because tumor antigens are self-antigens, it is likely that high-avidity T-cell receptors will be deleted from the repertoire (11). Adjuvants play an important role in combination with cancer peptide vaccine to enhance antigen 
immunogenicity and elicit the desired immune response. Montanide ISA-51, a water-in-oil emulsion composed of a mineral oil and a surfactant from the mannide monooleate family, is an adjuvant carrier with immunostimulatory effect that is widely used in WT1 peptide vaccine studies. The immune-enhancing effect of ISA-51 is suggested to be associated with depot formation (slowing down the release of antigens at the immunization site), inflammation (stimulating the recruitment of antigen-presenting cells) and lymphocyte trapping (stimulating the accumulation of lymphocytes in draining lymph nodes) $(12,13)$. However, Hailemichael et al. reported that persisting vaccine depots can induce specific $\mathrm{T}$ cell sequestration, dysfunction and deletion at the vaccination sites (14). OK-432, a lyophilized biological preparation containing cells of Streptococcus pyogenes $\mathrm{Su}$ strain treated with benzylpenicillin, has potent immunomodulation and therapeutic properties when applied in cancer treatment as a biological response modifier (15). Although little data are available on WT1 peptide vaccination therapy combined with OK-432 as an adjuvant, OK-432 was recently used as an adjuvant in WT1 peptide-pulsed DC vaccine for pancreatic cancer in Japan $(16,17)$. These trials suggested that some patients achieved survival benefits without serious adverse effects. Thus, OK-432 might be a potential candidate as an adjuvant for immunotherapy (17). Therefore, we investigated the safety of WT1 peptide vaccination therapy with OK-432 as an adjuvant in paediatric patients with solid tumors.

\section{Materials and Methods}

Trial design and patient eligibility. This clinical trial was approved by the Ethical Committee of Shinshu University School of Medicine on 8 May 2013 (approval number: 2297) and was registered in the University Hospital Medical Information Network Clinical Trial Registry (UMIN-CTR) as a Clinical Trial (Unique trial number: UMIN000011030) on 1 July 2013. Written informed consent to participate was obtained from each patient and/or guardian. The trial was conducted in accordance with the Declaration of Helsinki and International Conference Harmonization guidelines for Good Clinical Practice.

Eligibility criteria were as follows: age $<20$ years, patients having human leukocyte antigen (HLA)-A*24:02, HLA-A*02:01 or HLA$A * 02: 06$ allele, pathologically proven cancers, having been treated in accordance with standard clinical guidelines, patients having neither allergies to OK-432 nor to penicillin, with a Karnofsky performance status over $60 \%$ (18), an estimated survival duration of over 3 months and with maintained function of major organs.

WT1 vaccination. We used HLA-A*24:02-restricted mutant WT1 peptide (residues 235-243: CYTWNQMNL) and/or A*02:01/ A*02:06-restricted wild-type WT1 peptide (residues 126-134: RMFPNAPYL), both of which could be prepared at practice grade level and were derived from NeoMPS Inc $(19,20)$. Seven doses of HLA-A*24:02- or A*02:01/*02:06-restricted WT1 peptide (1-3 mg) mixed with $0.25-2 \mathrm{KE}$ of OK-432 were injected intradermally in the bilateral axillary and inguinal areas once every 2 weeks following the protocol of DC vaccination (21). Doses of WT1 peptide were adjusted according to the patient's body weight (BW) (1 mg of WT1 peptide for $\mathrm{BW}<10 \mathrm{~kg}, 2 \mathrm{mg}$ for $10 \mathrm{~kg}<\mathrm{BW}<20 \mathrm{~kg}, 3 \mathrm{mg}$ for BW $>20 \mathrm{~kg}$ ). Initial doses of OK-432 were adjusted according to the patient's BW (0.25 KE of OK-432 for BW <10 kg, $0.5 \mathrm{KE}$ for 10 $\mathrm{kg}<\mathrm{BW}<20 \mathrm{~kg}, 1 \mathrm{KE}$ for $\mathrm{BW}>20 \mathrm{~kg}$ ). The doses of OK-432 after second vaccination were adjusted based on vaccine-related toxicities. If both WT1 peptides were applicable to patients according to the HLA typing, one peptide was injected into the axillary and inguinal area at one side and the other one was injected at the opposite side.

Evaluation of WT1 peptide vaccine-related toxicities. Adverse effects including fevers and allergic reactions were monitored and graded according to the National Cancer Institute's Common Terminology Criteria for Adverse Events (CTCAE) Version 4.0. The skin reaction at the injection site was examined after each vaccination in all patients. Redness and induration were assessed after 24, 48 and 72 hours. Any reaction at the injection site was measured as the maximum diameter of redness and induration. A positive skin reaction was defined as an erythema of more than $3 \mathrm{~mm}$.

Evaluation of the immunological response. Peripheral blood mononuclear cells were obtained before initiating the first vaccination and at the completion of the seventh vaccination. The phenotypes of circulating T-cell populations were determined with fluorescenceactivated cell sorting by measuring the total $\mathrm{CD}^{+}$population, the $\mathrm{CD}^{+}$subpopulation, the $\mathrm{CD} 8^{+}$subpopulation and the activation markers HLA-DR on $\mathrm{CD}^{+}$cells and other, $\mathrm{CD} 19^{+}$and $\mathrm{CD}^{+} 6^{+}$ populations. We determined $\mathrm{CD} 4{ }^{+} \mathrm{CD} 25^{\text {int } / \text { high }} \mathrm{CD} 127^{\text {low }}$ cells as the regulatory T-cell population $(22,23)$. The WT1 tetramer assay was performed only in patients who received HLA-A*24:02-restricted mutant WT1 peptide in the CD3/CD8 double-positive population (19, 24). Enzyme-linked immunosorbent spot (ELISpot) assays were performed to examine WT1-specific interferon (IFN)- $\gamma$ production by $\mathrm{CD}^{+} \mathrm{T}$ cells called cytotoxic T lymphocytes (CTLs) $(19,24)$.

Immunohistochemical analyses of WT1 and antigen presentationrelated molecules. We analysed WT1, HLA class I and HLA-DR protein expression in primary tumor samples by the previously described method (25). In addition to this panel, we analysed the transporter associated with the antigen processing 1 (TAP1) using rabbit polyclonal anti-TAP1 antibody (ADI-CSA-620-E, Enzo Life Sciences, Inc., Farmingdale, NY, USA).

Statistical analyses. While we assessed the changes in lymphocyterelated phenotypes before and after vaccination with the Wilcoxon signed-rank test, differences in lymphocyte-related phenotypes between patients with/without WT1-specific CTL were analyzed with the Mann-Whitney $U$-test. We considered $p<0.05$ statistically significant. In this study, statistical analyses were performed using the EZR (26).

\section{Results}

Patients and disease characteristics. In total, 24 paediatric patients with solid tumors were enrolled. The diagnoses were brain tumors $(n=14)$, rhabdomyosarcomas $(n=5)$, neuroblastomas $(n=3)$, osteosarcomas $(n=1)$ and clear cell sarcoma of the kidney $(n=1)$. The median age of the patients was 7.5 
years (range $=2-19$ years). The ratio of male to female was 17:7. Of the 24 patients, 6 dropped out of this trial: 4 for aggravation of their general condition due to the affecting cancer, 1 because of a relapse of the original cancer and 1 because of the development of a second malignancy (myeloid leukaemia). The number of patients who received only HLA-A*24:02-restricted mutant or A*02:01/*02:06restricted WT1 peptide was 11 and 10 , respectively. Of the total, 3 patients received both WT1 peptides. Nobody dropped out due to WT1 vaccine-related toxicity. Table I shows the clinical characteristics and the immunological outcomes of patients who completed one course of WT1 peptide vaccination therapy.

Toxicity of the WT1 vaccination. The total frequency of vaccination was 126 times among the 18 patients who completed the trial. An adverse effect attributable to WT1 peptide vaccine was observed 77 times (61\%) in 16 patients (89\%): Grade-1 and -2 fevers were observed 20 times (16\%) in 10 patients and 3 times (2\%) in 3 patients, respectively, a Grade-1 reaction at the injection site was observed 53 times (42\%) in 13 patients. An anaphylaxis CTCAE Grade-3 was observed in a single case after the last vaccine was administered. The patient who developed anaphylactic shock was a nine-year-old male who had suffered from asthma, atopic dermatitis and hay fever. He developed anaphylactic shock immediately following the seventh injection of WT1 peptide vaccine. His allergic symptoms disappeared quickly after antihistamine and glucocorticoid were administered.

WT1-specific immune response after the vaccination. Exploratory analyses of the immune response consisted of assessment of the ELISpot assay to WT1 peptide and WT1 peptide/HLA-A $* 24: 02$-tetramer ${ }^{+} \mathrm{CD}^{+} \mathrm{CD}^{+} \mathrm{T}$-lymphocytes in peripheral blood of 18 patients who had completed this trial. The ELISpot and tetramer assays were performed in 18 and 10 patients, respectively, before and at the end of the trial. Of the 18,4 patients $(22 \%)$ were observed to demonstrate a WT1specific immune response in at least one assay at the end of one course of vaccination (Table I). When comparing the difference in lymphocyte-related phenotypes, including $\mathrm{CD}^{+}$, $\mathrm{CD}^{+}, \mathrm{CD}^{+}, \mathrm{HLA}-\mathrm{DR}$ on $\mathrm{CD}^{+}, \mathrm{CD} 19^{+}, \mathrm{CD}^{+} 6^{+}$and regulatory $\mathrm{T}$-cell, before and at the end of one course of vaccination, no significant change was observed. In addition, we could not observe significant differences between 4 patients with WT1-specific immunological responses and other negative groups. Of 4 patients who were diagnosed with WT1specific CTL, 1 patient (no. 8) demonstrated stable disease for 14 months under chemotherapy and the remaining 3 patients (no. 25, 39 and 44) presented with a progressive disease. Furthermore, the disease in patient no. 39 and 44 was uncontrollable irrespective of chemotherapy and/or radiotherapy before vaccination.
Expression of WT1 and antigen-presentation-related molecules in paediatric patients with solid tumors. We analysed 20 patient samples (brain tumor, 11; rhabdomyosarcoma, 5; neuroblastoma, 2; osteosarcoma, 1 and clear-cell sarcoma of the kidney, 1). All samples were WT1-positive. HLA class I also expressed highly (85\%); however, the expression rate of HLA-DR was low (55\%). The expression rate of TAP1 was also high (95\%) (Table II).

\section{Discussion}

Only one report has been published on WT1 vaccination therapy, targeting a relatively large number of paediatric patients with solid tumors (10). Sawada et al. reported that vaccination with HLA-A*24:02-restricted mutant WT1 peptide in Montanide ISA-51, in a clinical trial of 26 paediatric patients with haematologic or solid tumours, was well tolerated and safe. In our study, we used either HLA-A*24:02-restricted mutant WT1 peptide and/or A*02:01/A*02:06-restricted wild-type WT1 peptide in combination with a mixture of group A streptococcus $\mathrm{OK}$ 432. As in the previous report with WT1 peptide vaccines, most patients had only mild (Grade-1 or -2) toxicities during the course of vaccination, although 1 patient developed Grade-3 anaphylactic shock at the final administration of the vaccine. OK-432 is reported as an allergic-reaction-inducing agent (27). Furthermore, anaphylactic shock in this patient could be attributed to the presence of allergies such as asthma, atopic dermatitis and hay fever. Although 4 of 24 patients had allergies in this study, only this patient developed an allergic reaction. Perhaps, the differences between this patient and others could be the number of allergies and the presence allergy symptoms at the initiation of WT1 vaccination (the other 3 patients had only asthma and did not have any allergic symptoms at the beginning of vaccination). Therefore, this therapy should only be implemented after conducting a detailed interview for the patient's past history and family history. Patients with a history of allergic reaction should be closely monitored after vaccination. Furthermore, the patient who has multiplex and/or active allergic symptoms at the beginning of vaccination may have higher risk for allergic reaction.

The primary immunological objective of this trial was the assessment of the WT1-specific CTL responses following vaccination and the potency of the WT1 vaccine using the OK-432 as an adjuvant. In accordance with the recommendations of the Society for Biological Therapy (28), tetramer-based quantitative assays and ELISpot assays were used to determine T-cell responses. In this study, 4 of the 18 patients (22\%) were observed to have a WT1specific immune response in at least one assay with rather low potency. Van Driessche et al. summarized 21 clinical 


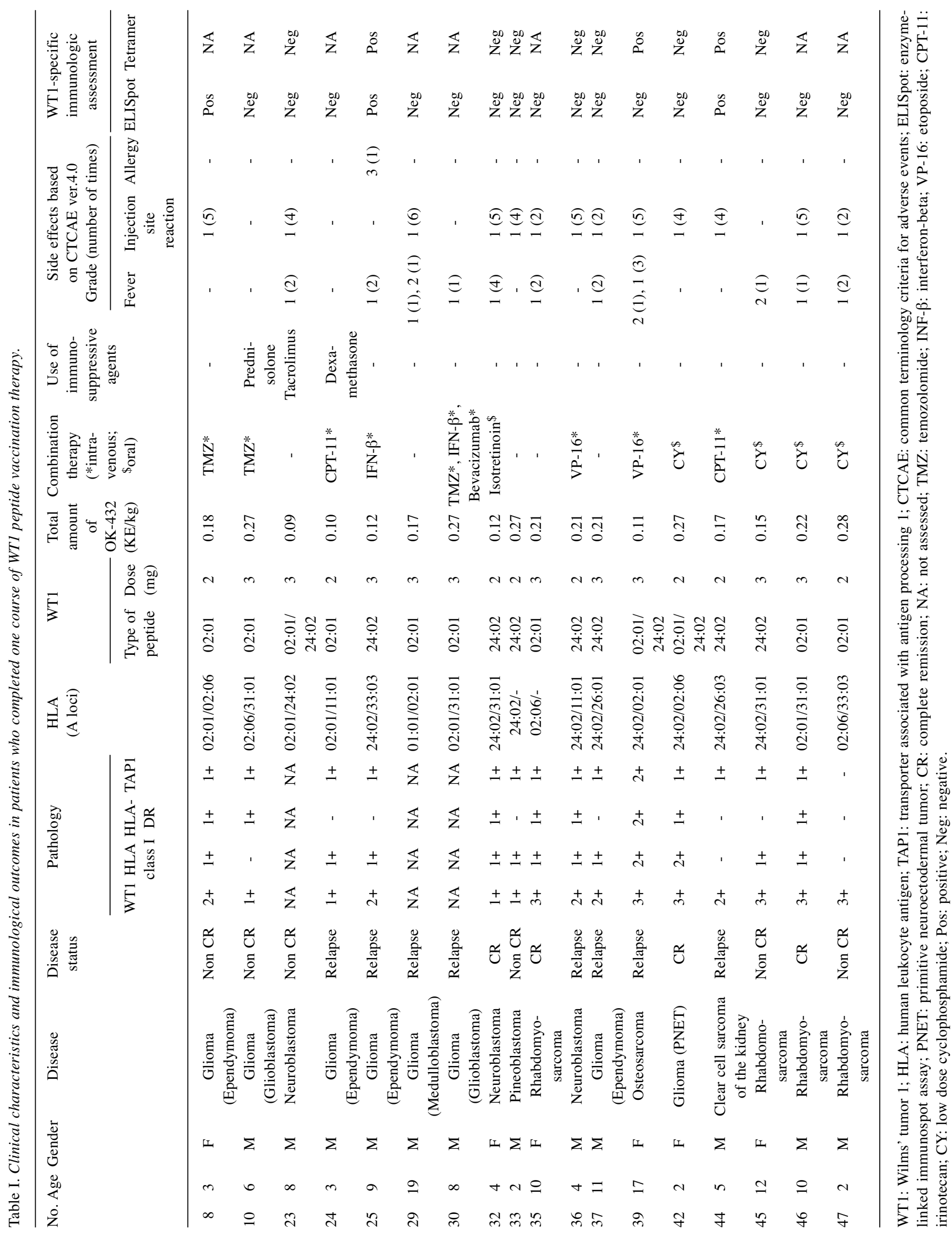


Table II. Immunohistochemical analyses of WT1 and antigen presentation-related molecules.

\begin{tabular}{|c|c|c|c|c|c|}
\hline Disease & No. of patients & WT1 & HLA class I & HLA-DR & TAP1 \\
\hline Brain tumor & 14 & $11 / 11(100 \%)$ & $10 / 11(91 \%)$ & $6 / 11(55 \%)$ & $10 / 10(100 \%)$ \\
\hline Ependymoma & 5 & $5 / 5$ & $5 / 5$ & $2 / 5$ & $5 / 5$ \\
\hline Glioblastoma & 3 & $1 / 1$ & $0 / 1$ & $1 / 1$ & $1 / 1$ \\
\hline Medulloblastoma & 2 & $1 / 1$ & $1 / 1$ & $0 / 1$ & $1 / 1$ \\
\hline Diffuse intrinsic pontine glioma & 1 & $1 / 1$ & $1 / 1$ & $1 / 1$ & NA \\
\hline Pineoblastoma & 1 & $1 / 1$ & $1 / 1$ & $1 / 1$ & $1 / 1$ \\
\hline Malignant transformation of craniopharyngioma & 1 & $1 / 1$ & $1 / 1$ & $1 / 1$ & $1 / 1$ \\
\hline Primitive neuroectodermal tumor & 1 & $1 / 1$ & $1 / 1$ & $0 / 1$ & $1 / 1$ \\
\hline Rhabdomyosarcoma & 5 & $5 / 5(100 \%)$ & $4 / 5(80 \%)$ & $2 / 5(40 \%)$ & $4 / 5(80 \%)$ \\
\hline Neuroblastoma & 3 & $2 / 2(100 \%)$ & $2 / 2(100 \%)$ & $2 / 2(100 \%)$ & $2 / 2(100 \%)$ \\
\hline Osteosarcoma & 1 & $1 / 1(100 \%)$ & $1 / 1(100 \%)$ & $1 / 1(100 \%)$ & $1 / 1(100 \%)$ \\
\hline Clear cell sarcoma of the kidney & 1 & $1 / 1(100 \%)$ & $0 / 1(0 \%)$ & $0 / 1(0 \%)$ & $1 / 1(100 \%)$ \\
\hline Total & 24 & $20 / 20(100 \%)$ & $17 / 20(85 \%)$ & $11 / 20(55 \%)$ & $18 / 19(95 \%)$ \\
\hline
\end{tabular}

WT1: Wilms' tumor 1; HLA: human leukocyte antigen; TAP1: transporter associated with antigen processing 1.

trials including both adults and children that administered with WT1 peptide. Of the 125 patients, 69 (55\%) were observed to have a WT1-specific immune response after vaccination. However, response rates were significantly different between haematological malignancies and solid tumors: Of 77 patients, $52(68 \%)$ were positive for haematological malignancies, and of 48 patients, 17 (35\%) were positive for solid tumors (29). This indicates that the acquisition of a WT1-specific immune response is considerably influenced by the type of disease. Although our acquisition rate of WT1-specific CTL seems to be still insufficient, this may be attributed to the specific immune system of the paediatric patients with solid tumors, inadequate vaccine frequency (in other reports, $64 \%$ of patients were administered vaccine 12 times compared to only 7 times in our study), differences in the WT1 peptide (A*24:02-restricted mutant WT1 peptide was administered in $83 \%$ of patients in other reports), the limited availability of solid tumor cases in this study, the heterogeneity in the disease status and the combination of chemotherapy and immunosuppressant therapy. In fact, no patient achieved WT1-specific immunological responses under treatment comprising immunosuppressive agents; for instance, steroid agents to prevent cerebral edema because of a brain tumor in 2 patients and tacrolimus for graft-versus-host disease after stem cell transplantation in 1 patient. Conversely, all 4 patients who were diagnosed with WT1-specific CTL were undergoing chemotherapy. However, the type of chemotherapy, including the degree of myelosuppression, varied in each patient. This result might indicate that while the combination of chemotherapy on the acquisition of WT1-specific CTL could be insignificant, the use of immunosuppressive agents could have adverse effects. The potency of vaccine might be also influenced by different adjuvant setting using OK-432 rather than the conventional Montanide ISA51. It has been reported that OK-432 strongly induces the maturation of DCs and that OK-432stimulated DCs can induce tumor antigen-specific CTLs $(15,30-33)$. Because our major aim was to assess the safety of WT1-peptide vaccine with OK-432, the acquisition rate of WT1-specific CTL and the clinical response should be evaluated in prospective trials. Although we could not conclude positive effect in our 4 patients who had a WT1specific immunological response in this study, the achievement of disease control before the induction of antitumor effect from WT1-specific CTLs seems imperative.

The prerequisite for a successful tumor-specific CTL response is HLA class I expression on the surface of cancer cells because the absence or down-regulation of HLA class I leaves the $\mathrm{T}$ cells incapable of recognizing the cancer cell (34). Loss or down-regulation of HLA class I has been described in human tumors of different origins at frequencies that range from $60 \%$ to $90 \%$ (35-37). In this study, the limitation of immunohistochemical analyses was the inability to assess tissue specimens from all patients. However, in our analysis of the expression of WT1 and antigen-presentation-related molecules, all samples were WT1-positive (15/15) and highly expressed HLA class I $(12 / 15)$. Moreover, TAP1, which is involved in the transport of antigens from the cytoplasm to the endoplasmic reticulum for association with major histocompatibility complex class I molecules, was positive in most samples (14/15). These results indicate that WT1specific CTL may be able to recognize and kill tumor cells if paediatric patients with solid tumors obtain a WT1specific immune response. 
In addition to its easy administration, peptide vaccine therapy has the advantage that multiple tumor-specific immune responses can be acquired at the same time by using a peptide cocktail vaccine that contains different cancer antigens $(38,39)$. Tumor-specific CTL therapy including peptide vaccine and DC-based therapy can also target intracellular antigens, unlike monoclonal antibody and chimeric antigen-receptor T-cell therapies. Nowadays, a new class of treatment, immune-checkpoint-inhibitor antibodies, which targets the immune system, has shown promising results in clinical trials (40). Immunecheckpoint-inhibitor antibodies such as nivolumab, atezolizumab, pembrolizumab inhibit programmed death-1 (PD-1)-mediated signalling by blocking PD-ligand 1 from binding to PD-1, allowing T-cell activation and immunesystem recognition. These antibodies assist in restoring antitumor activity. In several mice models, the combination of various cancer peptide vaccines and anti-cytotoxic Tlymphocyte-associated protein (CTLA)-4 or anti-PD-1 monoclonal antibody demonstrated additive and/or synergistic effects in specific T-cell induction and tumor growth control $(41,42)$. If the efficiency of the tumorspecific CTL response by cancer peptide vaccine is improved dramatically, combination therapy with immunecheckpoint-inhibitor antibodies may become a promising therapeutic strategy in the future.

In conclusion, we report that almost all WT1-peptide vaccinations were safe, but because an acute allergic reaction can always happen, it should be used with care. Because the immunological response rates of WT1-peptide vaccine still seemed to be insufficient in our small heterogeneous population, we recommend considering increasing times and/or the amount of WT1 peptide administered and narrowing the target population under the establishment of the appropriate eligibility based on the patient's disease, status, concomitant treatment and other clinical information in a future clinical study. WT1 is highly expressed together with antigen presentation-related molecules in paediatric patients with solid tumors. Improvement of the immunological induction efficiency and combination with other treatments may change the position of paediatric tumor-specific CTL therapy in the future.

\section{Conflicts of Interest}

The Authors declare no competing financial interests. S.H. is the inventor of patents for WT1 peptides (PCT/JP02/02794 and $\mathrm{PCT} / \mathrm{JP} 04 / 16336)$. This work was supported by JSPS KAKENHI Grant Number 16K10021.

\section{Acknowledgements}

The Authors would like to thank Mr. Shinsuke Ishikawa, Ms. Naoko Yamaoka and Ms. Yumiko Mizuno for supporting the immunological analysis.

\section{References}

1 Kaatsch P: Epidemiology of childhood cancer. Cancer Treat Rev 36(4): 277-285, 2010.

2 Mariotto AB, Rowland JH, Yabroff KR, Scoppa S, Hachey M, Ries L and Feuer EJ: Long-term survivors of childhood cancers in the United States. Cancer Epidemiol Biomarkers Prev 18(4): 1033-1040, 2009.

3 Call KM, Glaser T, Ito CY, Buckler AJ, Pelletier J, Haber DA, Rose EA, Kral A, Yeger H, Lewis WH et al: Isolation and characterization of a zinc finger polypeptide gene at the human chromosome 11 Wilms' tumor locus. Cell 60(3): 509-520, 1990.

4 Gessler M, Poustka A, Cavenee W, Neve RL, Orkin SH and Bruns GA: Homozygous deletion in Wilms tumors of a zincfinger gene identified by chromosome jumping. Nature 343(6260): 774-778, 1990.

5 Haber DA, Buckler AJ, Glaser T, Call KM, Pelletier J, Sohn RL, Douglass EC and Housman DE: An internal deletion within an $11 \mathrm{p} 13$ zinc finger gene contributes to the development of Wilms' tumor. Cell 61(7): 1257-1269, 1990.

6 Osaka M, Koami K and Sugiyama T: WT1 contributes to leukemogenesis: Expression patterns in 7,12-dimethylbenz[a] anthracene (DMBA)-induced leukemia. Int J Cancer 72(4): 696699, 1997.

7 Menke AL, van der Eb AJ and Jochemsen AG: The Wilms' tumor 1 gene: Oncogene or tumor suppressor gene? Int Rev Cytol 181: 151-212, 1998.

8 Oka Y, Tsuboi A, Fujiki F, Shirakata T, Nishida S, Hosen N, Nakajima H, Li Z, Kawase I, Oji Y and Sugiyama H: "Cancer antigen WT1 protein-derived peptide"-based treatment of cancer -toward the further development. Curr Med Chem 15(29): 30523061,2008

9 Oka Y, Tsuboi A, Oji Y, Kawase I and Sugiyama H: WT1 peptide vaccine for the treatment of cancer. Curr Opin Immunol 20(2): 211-220, 2008.

10 Sawada A, Inoue M, Kondo O, Yamada-Nakata K, Ishihara T, Kuwae Y, Nishikawa M, Ammori Y, Tsuboi A, Oji Y, KoyamaSato M, Oka Y, Yasui M, Sugiyama H and Kawa K: Feasibility of cancer immunotherapy with WT1 peptide vaccination for solid and hematological malignancies in children. Pediatr Blood Cancer 63(2): 234-241, 2016.

11 Melero I, Gaudernack G, Gerritsen W, Huber C, Parmiani G, Scholl S, Thatcher N, Wagstaff J, Zielinski C, Faulkner I and Mellstedt H: Therapeutic vaccines for cancer: An overview of clinical trials. Nat Rev Clin Oncol 11(9): 509-524, 2014.

12 Kaeberle: Function of carriers and adjuvants in induction of immune responses. Nervig R GP, Kaeberle $\mathrm{M}$ and Whetstone C (eds.). Iowa State University Press, USA, pp. 11-23, 1986.

13 Aucouturier J, Dupuis L and Ganne V: Adjuvants designed for veterinary and human vaccines. Vaccine 19(17-19): 2666-2672, 2001.

14 Hailemichael Y, Dai Z, Jaffarzad N, Ye Y, Medina MA, Huang XF, Dorta-Estremera SM, Greeley NR, Nitti G, Peng W, Liu C, Lou Y, Wang Z, Ma W, Rabinovich B, Sowell RT, Schluns KS, Davis RE, Hwu P and Overwijk WW: Persistent antigen at vaccination sites induces tumor-specific CD8(+) T cell sequestration, dysfunction and deletion. Nat Med 19(4): 465472, 2013.

15 Itoh T, Ueda Y, Okugawa K, Fujiwara H, Fuji N, Yamashita T, Fujiki H, Harada S, Yoshimura T and Yamagishi H: Streptococcal 
preparation OK432 promotes functional maturation of human monocyte-derived dendritic cells. Cancer Immunol Immunother 52(4): 207-214, 2003.

16 Kimura Y, Tsukada J, Tomoda T, Takahashi H, Imai K, Shimamura K, Sunamura M, Yonemitsu Y, Shimodaira S, Koido $\mathrm{S}$, Homma $\mathrm{S}$ and Okamoto M: Clinical and immunologic evaluation of dendritic cell-based immunotherapy in combination with gemcitabine and/or S-1 in patients with advanced pancreatic carcinoma. Pancreas 41(2): 195-205, 2012.

17 Kobayashi M, Shimodaira S, Nagai K, Ogasawara M, Takahashi H, Abe H, Tanii M, Okamoto M, Tsujitani S, Yusa S, Ishidao T, Kishimoto J, Shibamoto Y, Nagaya M, Yonemitsu Y and Therapy DCVSGatJSoIC: Prognostic factors related to add-on dendritic cell vaccines on patients with inoperable pancreatic cancer receiving chemotherapy: A multicenter analysis. Cancer Immunol Immunother 63(8): 797-806, 2014.

18 Schag CC, Heinrich RL and Ganz PA: Karnofsky performance status revisited: Reliability, validity, and guidelines. J Clin Oncol 2(3): 187-193, 1984.

19 Saito S, Yanagisawa R, Yoshikawa K, Higuchi Y, Koya T, Yoshizawa K, Tanaka M, Sakashita K, Kobayashi T, Kurata T, Hirabayashi K, Nakazawa Y, Shiohara M, Yonemitsu Y, Okamoto M, Sugiyama H, Koike K and Shimodaira S: Safety and tolerability of allogeneic dendritic cell vaccination with induction of Wilms tumor 1-specific T cells in a pediatric donor and pediatric patient with relapsed leukemia: A case report and review of the literature. Cytotherapy 17(3): 330-335, 2015.

20 Sakai K, Shimodaira S, Maejima S, Udagawa N, Sano K, Higuchi Y, Koya T, Ochiai T, Koide M, Uehara S, Nakamura M, Sugiyama H, Yonemitsu Y, Okamoto M and Hongo K: Dendritic cell-based immunotherapy targeting Wilms' tumor 1 in patients with recurrent malignant glioma. J Neurosurg 123(4): 989-997, 2015.

21 Shimodaira S, Hirabayashi K, Yanagisawa R, Higuchi Y, Sano $\mathrm{K}$ and Koizumi T: Dendritic cell-based cancer immunotherapy targeting Wilms' tumor 1 for pediatric cancer. In: Wilms tumor. van den Heuvel-Eibrink MM (ed.). Codon Publications, Brisbane (AU), 2016.

22 Liu W, Putnam AL, Xu-Yu Z, Szot GL, Lee MR, Zhu S, Gottlieb PA, Kapranov P, Gingeras TR, Fazekas de St Groth B, Clayberger C, Soper DM, Ziegler SF and Bluestone JA: CD127 expression inversely correlates with FoxP3 and suppressive function of human CD4+ T reg cells. J Exp Med 203(7): 17011711, 2006.

23 Seddiki N, Santner-Nanan B, Martinson J, Zaunders J, Sasson S, Landay A, Solomon M, Selby W, Alexander SI, Nanan R, Kelleher A and Fazekas de St Groth B: Expression of interleukin (IL)-2 and IL-7 receptors discriminates between human regulatory and activated T cells. J Exp Med 203(7): 1693-1700, 2006.

24 Higuchi Y, Koya T, Yuzawa M, Yamaoka N, Mizuno Y, Yoshizawa K, Hirabayashi K, Kobayashi T, Sano K and Shimodaira S: Enzyme-linked immunosorbent spot assay for the detection of Wilms' tumor 1-specific T cells induced by dendritic cell vaccination. Biomedicines 3(4): 304-315, 2015.

25 Shimodaira S, Hirabayashi K, Koya T, Higuchi Y and Sano K: Standard WT1 expression using immunohistochemistry. J Mol Biomark Diagn 7: 266, 2015.

26 Kanda Y: Investigation of the freely available easy-to-use software 'EZR' for medical statistics. Bone Marrow Transplant 48(3): 452-458, 2013.
27 Poldervaart MT, Breugem CC, Speleman L and Pasmans S: Treatment of lymphatic malformations with OK-432 (picibanil): Review of the literature. J Craniofac Surg 20(4): 1159-1162, 2009.

28 Keilholz U, Weber J, Finke JH, Gabrilovich DI, Kast WM, Disis ML, Kirkwood JM, Scheibenbogen C, Schlom J, Maino VC, Lyerly HK, Lee PP, Storkus W, Marincola F, Worobec A and Atkins MB: Immunologic monitoring of cancer vaccine therapy: Results of a workshop sponsored by the Society for Biological Therapy. J Immunother 25(2): 97-138, 2002.

29 Van Driessche A, Berneman ZN and Van Tendeloo VF: Active specific immunotherapy targeting the Wilms' tumor protein 1 (WT1) for patients with hematological malignancies and solid tumors: Lessons from early clinical trials. Oncologist 17(2): 250259, 2012.

30 Okamoto M, Furuichi S, Nishioka Y, Oshikawa T, Tano T, Ahmed SU, Takeda K, Akira S, Ryoma Y, Moriya Y, Saito M, Sone $S$ and Sato M: Expression of toll-like receptor 4 on dendritic cells is significant for anticancer effect of dendritic cell-based immunotherapy in combination with an active component of OK-432, a streptococcal preparation. Cancer Res 64(15): 5461-5470, 2004.

31 Nakahara S, Tsunoda T, Baba T, Asabe $\mathrm{S}$ and Tahara $\mathrm{H}$ : Dendritic cells stimulated with a bacterial product, OK-432, efficiently induce cytotoxic T lymphocytes specific to tumor rejection peptide. Cancer Res 63(14): 4112-4118, 2003.

32 Kuroki H, Morisaki T, Matsumoto K, Onishi H, Baba E, Tanaka M and Katano M: Streptococcal preparation OK-432: A new maturation factor of monocyte-derived dendritic cells for clinical use. Cancer Immunol Immunother 52(9): 561-568, 2003.

33 Ahmed SU, Okamoto M, Oshikawa T, Tano T, Sasai A, Kan S, Hiroshima T, Ohue H, Moriya Y, Ryoma Y, Saito M and Sato M: Anti-tumor effect of an intratumoral administration of dendritic cells in combination with TS-1, an oral fluoropyrimidine anticancer drug, and OK-432, a streptococcal immunopotentiator: Involvement of toll-like receptor 4. J Immunother 27(6): 432$441,2004$.

34 Thor Straten P and Garrido F: Targetless $\mathrm{T}$ cells in cancer immunotherapy. J Immunother Cancer 4: 23, 2016.

35 Garrido F, Ruiz-Cabello F, Cabrera T, Perez-Villar JJ, LopezBotet M, Duggan-Keen $M$ and Stern PL: Implications for immunosurveillance of altered HLA class I phenotypes in human tumors. Immunol Today 18(2): 89-95, 1997.

36 Marincola FM, Jaffee EM, Hicklin DJ and Ferrone S: Escape of human solid tumors from T-cell recognition: Molecular mechanisms and functional significance. Adv Immunol 74: 181273, 2000.

37 Seliger B, Cabrera T, Garrido F and Ferrone S: HLA class I antigen abnormalities and immune escape by malignant cells. Semin Cancer Biol 12(1): 3-13, 2002.

38 Hazama S, Nakamura Y, Takenouc0hi H, Suzuki N, Tsunedomi $\mathrm{R}$, Inoue $\mathrm{Y}$, Tokuhisa $\mathrm{Y}$, Iizuka $\mathrm{N}$, Yoshino $\mathrm{S}$, Takeda $\mathrm{K}$, Shinozaki H, Kamiya A, Furukawa $\mathrm{H}$ and Oka M: A phase I study of combination vaccine treatment of five therapeutic epitope-peptides for metastatic colorectal cancer; safety, immunological response, and clinical outcome. J Transl Med 12: 63, 2014.

39 Suzuki N, Hazama S, Iguchi H, Uesugi K, Tanaka H, Hirakawa K, Aruga A, Hatori T, Ishizaki H, Umeda Y, Fujiwara T, Ikemoto 
T, Shimada M, Yoshimatsu K, Shimizu R, Hayashi H, Sakata K, Takenouchi H, Matsui H, Shindo Y, Iida M, Koki Y, Arima H, Furukawa H, Ueno T, Yoshino S, Nakamura Y, Oka M and Nagano H: Phase II clinical trial of peptide cocktail therapy for patients with advanced pancreatic cancer: VENUS-PC study. Cancer Sci 108(1): 73-80, 2017.

40 Postow MA, Callahan MK and Wolchok JD: Immune checkpoint blockade in cancer therapy. J Clin Oncol 33(17): 1974-1982, 2015.

41 Williams EL, Dunn SN, James S, Johnson PW, Cragg MS, Glennie MJ and Gray JC: Immunomodulatory monoclonal antibodies combined with peptide vaccination provide potent immunotherapy in an aggressive murine neuroblastoma model. Clin Cancer Res 19(13): 3545-3555, 2013.
42 Karyampudi L, Lamichhane P, Scheid AD, Kalli KR, Shreeder B, Krempski JW, Behrens MD and Knutson KL: Accumulation of memory precursor CD8 T cells in regressing tumors following combination therapy with vaccine and anti-PD-1 antibody. Cancer Res 74(11): 2974-2985, 2014.

Received February 10, 2018

Revised February 26, 2018

Accepted February 27, 2018 